\title{
COMENTÁRIOS NO YOUTUBE: ESTUDO DE CASO DO CANAL VIIHROCHA
}

\author{
COMMENTS ON THE YOUTUBE: \\ A CASE STUDY OF THE VIIHROCHA CHANNEL
}

\author{
COMENTARIOS EN YOUTUBE: \\ ESTUDIO DE CASO DEL CANAL VIIHROCHA INTRODUÇÃO
}

Thaísa Bueno[i]

Even Grazielly de Sousa Escócio Silva[ii].

\section{RESUMO}

Apesar do seu potencial de participação, os comentários de leitores na internet também são,

constantemente, apontados como uma ferramenta que instiga o ódio por conta do teor dos textos ali inseridos, pois boa parte deles são incivilizados e intolerantes. Neste artigo, a proposta é estudar os comentários postados no YouTube, uma rede que incita a interação, mas que pela segmentação, também, seleciona seus seguidores por interesse temático. $\bigcirc$ estudo descritivo-analítico tem como recorte o canal Viihrocha, de Moda e Beleza, da vlogueira cearense Victória Rocha. A pesquisa foca nos comentários inseridos nos oito vídeos mais comentados entre setembro de 2015 e setembro de 2016. Ao todo foram analisados 1.519 comentários. $\bigcirc$ resultado aponta para uma audiência participativa, ainda que com pouco interesse na colaboração.

\section{Palavras-chave:}

Comentários; Canal Viihrocha; Interação; Audiência; YouTube.

\section{ABSTRACT}

Despite its potential for participation, the comments of readers on the Internet are also constantly pointed out as a tool that instigates hatred, due to the content of the texts inserted there, many of them uncivilized and intolerant. In this article, the proposal is to study the comments posted on YouTube, a network that encourages interaction, but that through segmentation, also selects its followers by thematic interest. The descriptive-analytical study is based on the Viihrocha channel, from Moda e Beleza, by a vloger from Ceará, Victória Rocha. The survey focuses on the comments inserted in the eight most commented videos between September 2015 and September 2016. In all, 1,519 comments were analyzed. The result points to a participatory audience, although with little interest in collaboration.

\section{Keywords:}

Comments; Viihrocha Channel; Interaction; Audience; YouTube.

\section{RESUMEN}

A pesar de su potencial de participación, los comentarios de los lectores en la Internet también se señalan constantemente como una herramienta que instiga al odio, debido al contenido de los textos insertados allí, muchos de ellos sin reglas e intolerantes. En este artículo, la propuesta es estudiar los comentarios publicados en YouTube, una red que promueve la interacción, sin embargo, también selecciona a sus seguidores por interés temático. El estudio descriptivoanalítico hace el análisis del canal Viihrocha, de Moda y Belleza, de la "blogueira" de Ceará, Victória Rocha. La encuesta se centra en los comentarios insertados en los ocho videos más comentados entre septiembre de 2015 y septiembre de 2016. En el total, se analizaron 1,519 comentarios. El resultado apunta a una audiencia participativa, aunque con poco interés en la colaboración.

\section{Palabras clave:}

Comentarios; Canal Viihrocha; Interacción; Audiencia; YouTube. 


\section{INTRODUÇ̃̃O}

Com mais de um bilhão de usuários contabilizados em 2016, segundo dados do próprio provedor, o YouTube surge e se estabelece como uma rede de criação e compartilhamento de conteúdo audiovisual, desde a produção amadora até o material profissional, movimentando usuários, clientes e anunciantes (GILLESPIE, 2010). Devido à sua popularização, os vídeos exibidos ali podem ser acessados por diferentes pessoas, simultaneamente, gerando bilhões de visualizações e criando ídolos e celebridades digitais. "Eu chamo isso de a grande sedução. [...]", (KEEN, 2009, p. 19-20).

Porém, essa não é a única especificidade da rede que permite e instiga a interação entre o criador de conteúdo e o seu público. Recursos como "Visualizações", "Gostei", "Não gostei", "Compartilhamentos", "Inscrições" e "Comentários", além de se apresentarem como marcas de monitoramento de dados da audiência, também, são recursos que instigam a sociabilidade do público com o produtor desse material, os YouTubers. "Por comunicarem à audiência o que é contabilizado como popular no YouTube, essas métricas também têm um papel ativo na criação da realidade do que é popular no YouTube: elas não são meramente descritivas, mas também performáticas", (BURGESS; GREEN, 2009, p. 64).

Essa é, essencialmente, a questão norteadora desta pesquisa: identificar os modos de interação e o comportamento das audiências nessa rede social. A proposta é estudar os comentários postados no YouTube, um espaço que incita a interação, mas que pela segmentação, também, seleciona seus seguidores por interesse temático. $O$ estudo descritivoanalítico tem como recorte o canal Viihrocha de Moda e Beleza, da vlogueira cearense Victória Rocha. A pesquisa foca nos comentários inseridos nos oito vídeos mais comentados das categorias levantadas neste estudo entre setembro de 2015 e setembro de 2016. Ao todo foram analisados 1.519 comentários. O objetivo foi identificar e catalogar os modos de interação da audiência com a vlogueira Victória Rocha para saber mais sobre o comportamento do público que comenta conteúdos segmentados.

O estudo se justifica porque o YouTube apresenta um número de usuários estratosféricos que, de acordo com dados da empresa, passam mais de uma hora todos os dias vendo as postagens do canal (YOUTUBE, 2020, online) e, além disso, disponibiliza recursos que instigam a interação, como os comentários de leitores, espaço que permite discutir o conteúdo, relacionar-se com outros usuários ou mesmo com - produtor do material postado. Os comentários, foco deste estudo, são, de fato, um ponto sensível da análise, por serem apontados, constantemente, como ferramentas que instigaram o ódio e a discriminação. Inclusive, pesquisa realizada por Bueno et al. (2016) mostrou que quase metade das pessoas que leem ou escrevem comentários na internet acredita que a ferramenta serve para o acirramento de ânimos e a manutenção de preconceitos.

Pertinente a essa questão, ÁvilaZesatti (2015) defende que devido à suscetibilidade das redes virtuais, empresas de todos os tipos, bem como figuras públicas e cidadãos comuns, que em algum momento publicam conteúdos, estão sujeitos a lidar com comentários nem sempre positivos. Sakamoto (2016) é mais enfático e defende que os comentários são, na sua maioria, negativos. A questão é tão controversa que alguns veículos tradicionais, inclusive, discutem a necessidade real da manutenção ou exclusão da plataforma.

Quando a plataforma dos comentários incorporada ao jornalismo, nos blogs, a partir de 1997 poucas regras norteavam esse formato de interação. $\mathrm{Na}$ época, quando o modelo migrou para os sites de notícia a maior discussão era esse modelo de interação direta não poria em risco a profissão do jornalista. Ou seja, a preocupação era menor em controlar o que se dizia nesse espaço, mas em saber em que medida essa ferramenta migraria cada vez mais para transformar o cidadão em um produtor de notícias e, portanto, em concorrente. (...) De qualquer forma, seja pelas críticas pela incivilidade seja pela falta de estrutura física e de pessoal para dar função efetiva aos comentários o fato é que a ferramenta tem sido um assunto delicado nas redações, que ainda discutem sobre manter ou não a plataforma, ou como torná-la menos subutilizada (BUENO, 2015 p. 221-222) 
Diante do exposto, este estudo quis discutir modos de interação por meio de comentários no YouTube, numa página de produção no Nordeste, afim de contribuir para investigações de cunho regional. O objeto de análise é o canal Viihrocha, voltado para produções de moda e beleza e assinado pela cearense e designer de moda Victória Rocha, que acumulava um total de 4.913.015 visualizações e 122.672 inscritos em 2016. A escolha se justifica porque a temática moda e beleza é uma das que mais fazem sucesso na rede. De acordo com pesquisas do Think With Google (2016a), ferramenta de marketing do Google, são milhões de pessoas que consomem conteúdo desse segmento no YouTube, seja por conta da resenha de produtos, de tutoriais ou na busca de inspiração de roupas.

O YouTube destaca-se como fonte de informação estratégica, pois representa uma referência potencial, no atendimento das demandas do mercado de moda e beleza, além de apresentar um papel considerável como fonte inovadora, pois se conceitua como ferramenta para a aplicação de novas ideias em qualquer serviço, produto ou processo (SANTOS; SILVA; ZATTAR, 2016, p. 90).

Ainda a respeito disso, as pesquisas do Think With Google também mostraram que um em cada dois amantes de moda e beleza já assistiu algum vídeo desse nicho. Eles também afirmam que a maioria do público que consome esse tipo de vídeo é do sexo feminino, apesar de 21\% serem do sexo oposto, e que 68\% do públicoalvo está na faixa etária entre 18 e 34 anos.
O canal da cearense, criado em fevereiro de 2007, foi selecionado porque a autora, formada em Design de Moda pela Faculdade Católica do Ceará, tem atraído milhares de seguidores nas suas redes sociais[1] com produções de moda popular e reconhecimento de famosos desse setor. O seu papel na rede já Ihe rendeu convites para trabalhar com marcas nacionais e internacionais e, inclusive, sua primeira viagem internacional para Riviera Maya, no México, em março de 2015, com grandes blogueiras do cenário: Gabriela Sales[2] e Mari Dalla[3]. Durante o período de análise, setembro de 2015 a setembro de 2016, foram registrados 5.150 comentários no canal. Todavia o estudo embasou-se em 1.519 deles selecionados a partir de critérios descritos na etapa metodológica.

\section{METODOLOGIA}

método de pesquisa utilizado neste levantamento foi o Estudo de Caso, aliado à Análise de Conteúdo. Embora a definição de estudo de caso abarque diferentes concepções, conforme a área utilizada, seja nas ciências humanas ou sociais aplicadas, partimos da orientação de Ventura (2007, p. 385): "geralmente organizada em torno de um pequeno número de questões que se referem ao como e ao porquê da investigação". No levantamento aqui apresentado a pergunta norteadora foi: como os internautas utilizam a ferramenta de comentários no canal estudado?

Para além da pergunta de pesquisa, conforme Gil (1995), ao adotar essa metodologia o pesquisador passa por quatro fases de investigação: a) delimitação da unidade-caso a ser estuda, neste caso o canal do YouTube; b) coleta de dados, nesta pesquisa foram os comentários postados; c) seleção, análise e interpretação dos dados, neste trabalho temos a análise de conteúdo e os teóricos da cibercultura discutidos no referencial teórico, como embasamento; e, por fim d) elaboração do relatório.

Sobre a Análise de Conteúdo, Moraes (1999) pondera que é uma ferramenta que descreve, sistematicamente,

qualitativamente

quantitativamente, o objeto de análise por meio de uma interpretação. Ainda nesse âmbito, Bardin (1977, p. 42) diz que essa técnica se propõe a obter "indicadores (quantitativos ou não) que permitam a inferência de conhecimentos relativos às condições de produção/recepção destas mensagens".

Moraes (1999) defende que o processo de análise de conteúdo se constitui em cinco etapas: preparação das informações, transformação do conteúdo em amostras, categorização ou classificação, descrição e interpretação. Bardin (2011) acrescenta que, além dessas escolhas, são definidos a problemática e a formulação de hipóteses para a interpretação final do conteúdo, definindo esse procedimento em três fases: pré-análise, exploração do material e, por fim, inferência e interpretação. Além disso, Bardin (2011, p. 123) acrescenta que "nem todo o material de análise é susceptivel de dar lugar a uma amostragem e, nesse caso, mais vale abstermo-nos e 
reduzir o próprio universo (e, portanto, o alcance da análise) se este for demasiado importante".

Gaskell (2002) ainda destaca que a utilização da descrição detalhada nesse procedimento é "uma base para construir um referencial para pesquisas futuras e fornecer dados para testar expectativas e hipóteses desenvolvidas fora de uma perspectiva teórica específica" (GASKELL, 2002, p. 65).

A partir de tais orientações metodológicas, o presente estudo buscou, por meio da identificação do objeto de análise e delimitação do tema e recorte temporal, uma categorização de tipos de comentários nos respectivos conteúdos feitos pela vlogueira Victória Rocha a fim de analisar o comportamento dos inscritos ao comentar em cada editoria do canal. Além da coleta de dados, foi utilizado o uso da entrevista por Whatsapp com a autora do canal.

\section{YOUTUBERS, VLOGGERS E O CONVITE AO ENGAJAMENTO}

O termo YouTuber surgiu logo depois da origem da plataforma em 2006, mas só no final de 2016 D Dicionário de Inglês Oxford reconheceu a expressão e adicionou-a como parte da sua coleção cujo significado é "um usuário frequente do website de compartilhamento de vídeos YouTube, especialmente quem produz e aparece nos vídeos do site" (OED, 2016, online, tradução nossa)[4].

Normalmente, os
YouTubers são donos de
um canal com publicações
periódicas de vídeos no
YouTube-
geralmenter produzidos,

gravados e editados por eles mesmos. O termo também se refere a figuras populares do YouTube,

webcelebridades, aqueles que concentram mais visualizações e inscritos em seus canais (FIGUEIRA, BASSANI, EMERIM, 2016, s/p.).

Jenkins, Ford, Green (2014) e Dornelles (2014) acrescentam que esses produtores de conteúdo também podem, ou deveriam, ser denominados de vloggers - palavra derivada de blogger com adição de vídeo. Isso porque tais produtores, na sua maioria, adaptam o conteúdo original dos seus blogs às postagens imagéticas, como uma espécie de complementação. Esse, inclusive, é o caso de Victória Rocha, que desde 23 de fevereiro de 2011 mantém o blog Viih Rocha- anteriormente com o nome Todo Estilo- e que em agosto de 2011 ingressou no YouTube.

É importante notar que YouTubers ou vloggers são denominados assim "por meio do engajamento combinado e ativo no espaço, em vez de simplesmente distribuírem vídeos através deste" e "são super usuários que desenvolvem públicos e carreiras de sucesso ao responder a comentadores e visitantes, convidando-os explicitamente a dar respostas e a fazer assinaturas" (JENKINS; GREEN; FORD 2014, p. 128). Por essa razão, é comum que respondam comentários e convidem o público para se inscrever no canal, dar sua opinião e acessar outras redes sociais e sites que complementam aquela página. Whindersson Nunes, o YouTuber com mais inscritos no Brasil[5], é um exemplo de como a interação nessa rede é, efetivamente, um valor simbólico importante.

Whindersson, no final de todos os seus vídeos, sempre convida sua audiência a interagir com o conteúdo de alguma maneira, seja nos comentários do YouTube ou em outras redes sociais. Ele pede que seus fãs comentem se já passaram ou não por uma situação semelhante e também pede que eles compartilhem o conteúdo com amigos que tenham passado por algo semelhante. Esse pedido explícito, acompanhado do pedido de inscrição e like no canal, faz as pessoas agirem dessa forma contribuindo para aumentar o engajamento geral do canal e para que Whindersson se torne conhecido por mais gente. (THINK WITH GOOGLE, 2016d, online)

Com tanto estímulo, não é de estranhar que a audiência se manifeste sobre o que assiste postando comentários com sugestões do que poderia ser gravado, questionando o produtor sobre algo ainda não esclarecido e conversando com outros comentaristas promovendo assim uma rede de interação social e uma cultura participativa.

O YouTube é utilizado de várias maneiras diferentes por cidadãosconsumidores por meio de um modelo híbrido de envolvimento com a cultura popular - parte produção amadora, parte consumo criativo. Do ponto de vista da audiência, é uma plataforma que fornece acesso à cultura ou uma plataforma que permite aos seus consumidores atuar como produtores? Essa amplitude é a fonte 
da diversidade e alcance do YouTube [...]. Claramente, é tanto um agente das transições culturais e econômicas que estão de alguma maneira atrelada às tecnologias digitais, à internet e à participação mais direta dos consumidores (BURGESS; GREEN, 2009, p. 32).

Esse processo é considerado um item significativo da interatividade e pressupõe pelo menos três tipos de interação: aquela em que o consumidor compartilha sua opinião através dos múltiplos canais e cujo conteúdo de interesse é postado; outra em que o consumidor interage com um diferente consumidor, expondo suas ideias de formas semelhantes ou contrárias; e a terceira, na qual o consumidor se torna criador de conteúdo (WARD, 2007).

Para Primo e Smaniotto (2006), os comentários de leitores na internet são ícones de participação, pois dentro desse ambiente há espaço para que o comentador se torne parte do universo midiático que consome e debata sobre ele ou outros assuntos. Barbosa (2001, online) ressalta que "muitas vezes, dependendo do assunto noticiado, o interesse despertado junto do público é elevado e os comentários transformam-se num fórum, dado que se estabelece um relacionamento entre diferentes participantes".

Os comentários, nesse sentido, são uma ferramenta que contribui para a construção de uma mídia mais democrática. Tanto é assim, que de acordo com Bueno et all (2016) quando as pessoas não comentam, elas leem as postagens. $O$ estudo também enfatiza que quem costuma comentar com mais frequência procura opinar em editorias consideradas amenas, como moda, variedades, comportamento e outras.

Não obstante, Bueno e Reino (2014, p. 79) afirmam que devido a uma estrutura bastante utilizada em portais de notícias - atualmente configurada em um sistema similar no YouTube - o recurso de classificar comentários pelos mais lidos e curtidos, ordem de postagem, respostas, entre outros, além de instigar a interação, revela que quem produz conteúdo inclina-se, a saber, o que o comentarista está escrevendo e o que está buscando.

\section{YOUTUBE}

Y YouTube surgiu em fevereiro de 2005. Ele é resultado do desejo de três colegas de trabalho norte-americanos Chad Hurley, Steve Chen e JawedKarim - em compartilhar vídeos com seus amigos (BURGESS; GREEN, 2009). No ano seguinte, em outubro, foi anunciada sua compra pelo Google (um site de buscas na internet) por 1,65 bilhão de dólares. Inicialmente, o YouTube limitava o upload de vídeos de até 10 minutos de duração. Atualmente, o site libera o upload de vídeos com mais de 15 minutos contendo tamanho máximo de arquivo de até 128 GB. Ele também oferece $O$ serviço de monetização para criadores de conteúdos lucrarem com anúncios em seus vídeos desde que não infrinjam as regras de direitos autorais; também permite que o YouTuber faça transmissão ao vivo e a incorpore em outros ambientes. Oferece editor de vídeos dentro da própria rede e até financiamento por fãs.

Burgess e Green (2009) alegam que o YouTube é um dos maiores sites do início do século 21 porque:

Y YouTube não estabeleceu limites para o número de vídeos que cada usuário poderia colocar online via upload, ofereceu funções básicas de comunidade, tais como a possibilidade de se conectar a outros usuários como amigos, e gerava URLS e códigos HTML que permitiam que os vídeos pudessem ser facilmente incorporados em outros sites, um diferencial que se aproveitava da recente introdução de tecnologias de blogging acessíveis ao grande público. Exceto pelo limite de duração dos vídeos que podiam ser transferidos para o servidor, o que o YouTube oferecia era similar a outras iniciativas de vídeos on-line da época. (BURGESS; GREEN, 2009, p. 17).

Ainda nesse quesito Jawed Karim apud Gannes (2006, online) acrescenta que a inserção de comentários no ambiente, a permissão de compartilhamento de vídeos e o código embed, que concede o direito de inserir o vídeo em outra rede para reproduzi-lo, foi o que tornou o site popular.

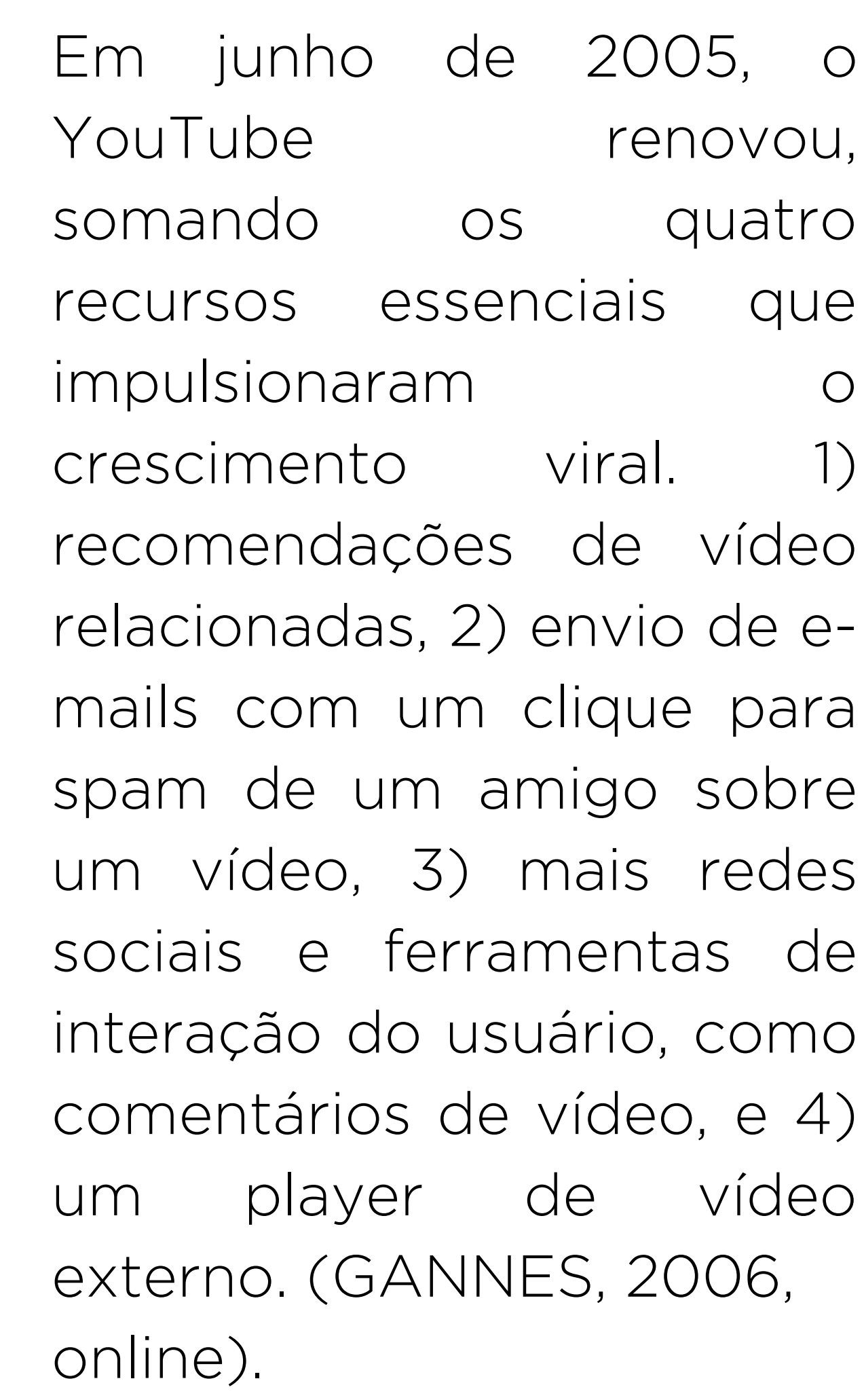


No entanto, a divisão por categorias muito generalistas e que efetivamente não contemplam o conteúdo tem sido, constantemente, apontada como um problema, particularmente porque dificultam bastante a navegação e a busca no site. Atualmente, o YouTube é dividido em treze categorias: Animais; Ciência e tecnologia; Educação; Entretenimento; Esportes; Filmes e desenhos; Humor; Instruções e estilo; Música; Notícia e política; Pessoas e blogs; Veículos; Viagens e eventos. Moda e Beleza, por exemplo, que inclusive é apontada como um nicho de destaque não é contemplada nessa seleção.

No YouTube o usuário que realizar essa busca baseado nas categorias disponibilizadas poderá facilmente encontrar música dentro de instruções e estilo, ou pessoas e blogs categorizados como entretenimento. Sem uma palavra-chave específica é muito difícil encontrar o conteúdo que se está procurando. (SERRANO: PAIVA, 2008, p.7).

\section{MODA E BELEZA NO YOUTUBE: O CANAL VIIHROCHA}

De acordo com o Think With Google (2016b), 50\% das mulheres que consomem o setor de Moda e Beleza do YouTube acreditam que esse é - melhor lugar para interagir com os criadores de conteúdo. Os dados ratificam essa opinião, já que estão presentes nos mais de 5,7 milhões de comentários dos principais canais do ramo.

Para o público que consome Moda e Beleza, o brilho não vem só do conteúdo. A gente passou a ter uma relação de cumplicidade com quem cria esses conteúdos Como? As blogueiras deixaram de ser só referência e viraram amigas. Com seus conselhos, elas estão ajudando a criar uma nova cultura de moda e beleza. E, de quebra estão influenciando o comportamento de toda essa geração. Pode reparar que as blogueiras não colocam regras. Elas só apontam os caminhos, para a audiência assumir a partir dali, com liberdade (THINK WITH GOOGLE, 2016c, online).

O site ainda acrescenta que mais da metade dessa população acessa canais do nicho pelo menos uma vez por dia porque consideram como experts os produtores do conteúdo, ainda que nem todos os responsáveis pelas páginas possam, formalmente, ser avaliados como especialistas. É o caso da YouTuber objeto de estudo deste artigo, Victória Rocha. Embora possua formação em Design de Moda, seu canal não se limita à sua especialidade, mas, também, busca incluir materiais sobre viagens, beleza, fotografia, gastronomia decoração e bastidores do seu dia-a-dia.

Com mais de 112 mil inscritos, a conta criada em fevereiro de 2007 - inserida na categoria Guias e Estilo- só passou a exibir vídeos em agosto de 2011, quando a autora compartilhou um tutorial de beleza sobre como fazer uma trança em cascata[6]. O vídeo chegou a receber quase um milhão de visualizações, entretanto os comentários estão inativos. Conforme Victória Rocha (2017), o recurso foi desativado porque muitas pessoas que não conheciam o seu trabalho comentavam de forma incivilizada, desacatando a autora.

Figura 1. Página principal do cana Viihrocha

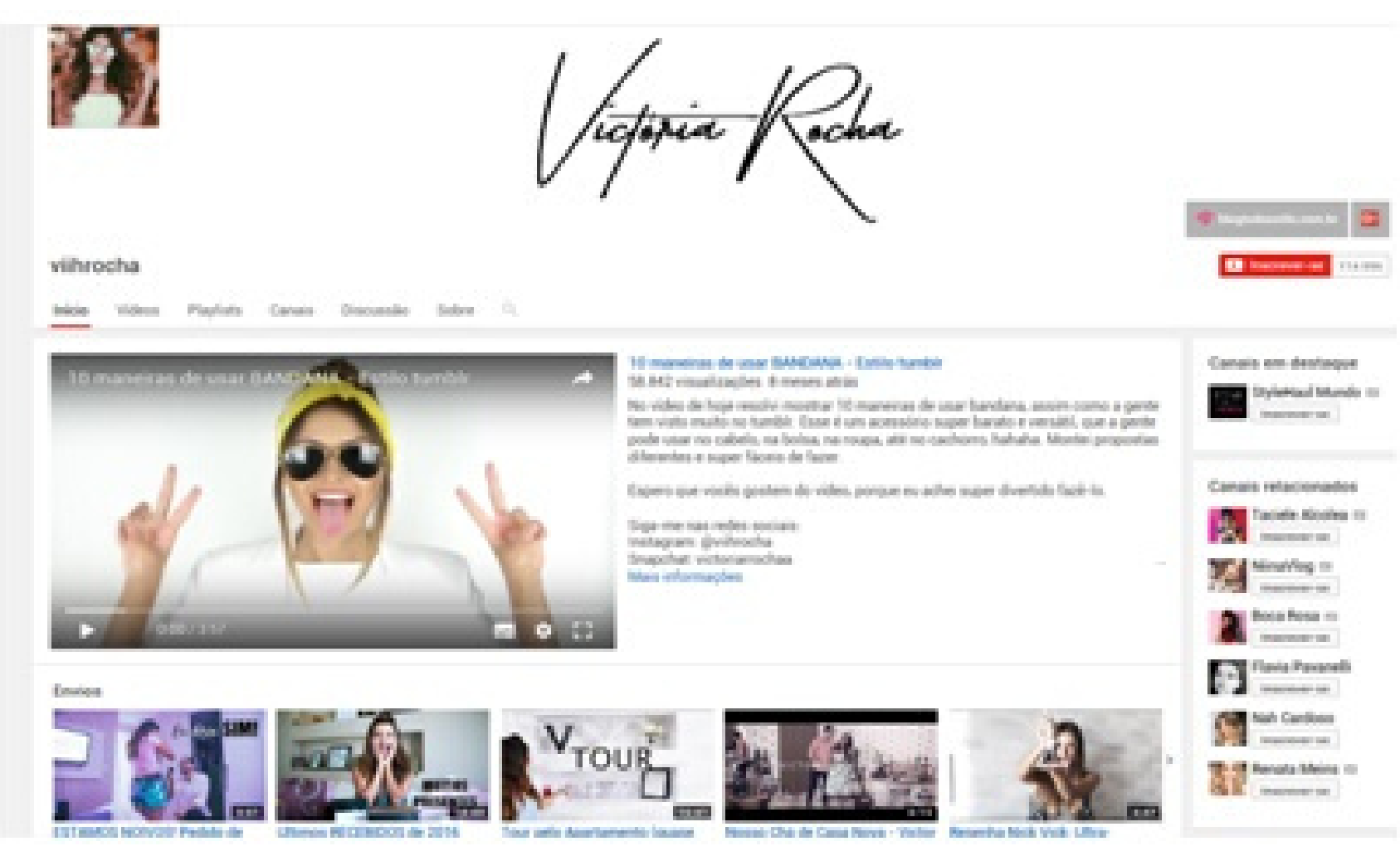

Fonte: Captura de tela (2017)

De agosto de 2011 a novembro de 2016 foram totalizados 202 vídeos publicados. Entretanto, o canal só passou a ter um fluxo contínuo de vídeos em 2015, quando a vlogueira ampliou, significativamente, a quantidade de conteúdos patrocinados diretamente e indiretamente por marcas.

\section{ANÁLISE DOS COMENTÁRIOS PRESENTES NO CANAL VIIHROCHA}

No período de setembro de 2015 a setembro de 2016 o canal Viihrocha publicou 50 vídeos. 0 montante não chega a ser uma publicação por semana durante a observação, o que permite ponderar que se não tem a frequência, ou atualização, como um diferencial. A diversidade da produção, ao que parece, é o que atrai 0 público. Das publicações encontradas no canal, podem-se identificar as seguintes categorias, organizadas a partir daquilo que era mais latente no conteúdo postado:

a) Vídeos de Viagens: Nessa categoria a autora dá dicas de viagem. Ela explora bastante o caráter de proximidade e adota uma linguagem que convida o 
público conhecer o local onde se hospeda e lugares a visitar e consumir.

b) Vídeos de Moda: Nessa categoria a autora produz conteúdos que abordam looks[7] em movimento para a melhor visualização das peças no corpo até orientações de como usar determinada roupa em várias situações.

c) Vídeos de Caráter Pessoal: Nessa categoria a autora compartilha com os inscritos detalhes do seu dia-a-dia ou da sua semana, também conhecidos como dailyvlogs. Além disso, podem conter desabafos, notícias pessoais e até tour pela casa ou algum cômodo, dando detalhes de decoração e organização.

d) Vídeos de Recebidos: Nessa categoria a autora mostra aos fãs itens que recebeu e acumulou durante um determinado período, ou seja, os press kits[8].

e) Vídeos de Colaboração: Nessa categoria é sempre aparente a presença de uma ou mais figuras que podem ser amigas, o namorado ou outros YouTubers conhecidos da autora que participam no canal. Geralmente, abordam-se temas diversos.

f) Vídeos de Beleza: Nessa categoria a autora costuma compartilhar dicas de produtos para usar no cabelo e mostra como fazer algum penteado ou maquiagem.

g) Vídeos de Publieditorial: Nessa categoria as empresam pagam para criar conteúdo sobre algo específico, mas fica aparente para o público que se trata de publicidade. h) Vídeos de Tecnologia e Fotografia: Aqui a autora compartilha com os usuários dicas de fotografia, aplicativos para editar fotos, entre outras inovações de tecnologia.

Uma vez identificadas as categorias de conteúdo mais comumente postadas na página da YouTuber, o objetivo do trabalho foi entender os modos de interação da audiência com essas postagens para saber, efetivamente, se há maneiras diferentes de comportamento

do comentador em conteúdos distintos.

Para isso a pesquisa buscou: analisar os comentários do vídeo com mais postagens de leitores em cada editoria, afim de saber qual conteúdo recebe mais interação e que tipo de ponderação aufere; demarcar se havia alguma mudança no comportamento do comentador ao assistir e comentar em diferentes categorias; identificar qual tipo de comentário a autora responde; e, por fim, categorizar os formatos de comentários mais usuais, analisando seu conteúdo.

Das oito categorias de conteúdo produzidas pela vlogueira no período analisado foram contabilizados 5.150 comentários. A descrição detalhada desses posts fica melhor visualizada no quadro que segue.

Quadro 1. Números de comentários recebidos nas categorias durante 0 período de análise

\begin{tabular}{|c|c|}
\hline Conteúdo & Comentários \\
\hline Caráter Pessoal & 1.170 \\
\hline Moda & 235 \\
\hline
\end{tabular}

\begin{tabular}{|c|c|}
\hline Beleza & 432 \\
\hline Recebidos & 392 \\
\hline $\begin{array}{l}\text { Tecnologia } \\
\text { e Fotografia }\end{array}$ & 102 \\
\hline Viagens & 558 \\
\hline Colaboração & 2.022 \\
\hline Publieditorial & 239 \\
\hline
\end{tabular}

Fonte: Elaboração das autoras (2020).

Um dado que chama atenção nessa descrição inicial é que apesar da temática Moda e Beleza ser o foco principal do canal da YouTuber, as duas categorias que abordam esse assunto, juntas, receberam apenas $\quad 13 \%$ dos 5.150 comentários. Já os vídeos de Colaboração e Caráter Pessoal representam mais do que metade desse total, com 61,9\%. Prosseguindo com a análise foi realizado um recorte entre as categorias, delimitando os vídeos mais comentados de cada uma delas, que resultou em 1.519 comentários.

Quadro 2. Categorias e os seus respectivos vídeos mais comentados

\begin{tabular}{|c|c|c|}
\hline Categ. & $\begin{array}{l}\text { Títulos dos } \\
\text { Vídeos mais } \\
\text { Comentados }\end{array}$ & Coments. \\
\hline Publi & $\begin{array}{l}5 \text { dicas para } \\
\text { o seu cabelo } \\
\text { crescer } \\
\text { mais rápido }\end{array}$ & 65 \\
\hline Pessoal & $\begin{array}{c}\text { Uma nova } \\
\text { fase das nossas } \\
\text { vidas! }\end{array}$ & 268 \\
\hline Moda & $\begin{array}{c}6 \text { looks com lace } \\
\text { up flats I get the } \\
\text { look }\end{array}$ & 117 \\
\hline Beleza & $\begin{array}{c}4 \\
\text { penteados estilo } \\
\text { tumblr }\end{array}$ & 238 \\
\hline Recebidos & $\begin{array}{l}\text { Recebidos de } \\
\text { outubro }\end{array}$ & 148 \\
\hline
\end{tabular}




\begin{tabular}{|l|c|c|}
\hline $\begin{array}{l}\text { Tec. } \\
\text { e foto }\end{array}$ & $\begin{array}{c}\text { Como } \\
\text { edito minhas fotos } \\
\text {-apps preferidos, } \\
\text { branquear foto }\end{array}$ & 100 \\
\hline Viagens & $\begin{array}{c}\text { Top of the rock - } \\
\text { vlog new york, } \\
\text { episódio 2 }\end{array}$ & 70 \\
\hline Colab. & $\begin{array}{c}\text { Invadindo } \\
\text { o closet: } \\
\text { tacielealcolea \#1 }\end{array}$ & 513 \\
\hline
\end{tabular}

Fonte: Elaboração das autoras (2020).

Para atender o objetivo desta pesquisa no que tange categorizar os modos de interação por meio de comentários nos diferentes conteúdos, buscou-se identificar os modelos mais comuns de posts dos usuários. São eles:

a) Identificação com o autor: $O$ comentador identifica-se com o autor e/ou alguma situação compartilhada no vídeo;

b) Elogios: O comentador elogia o autor ou o conteúdo ali oferecido;

c) Interação com outros usuários: $\quad$ comentador conversa com outro comentador;

d) Resposta do Autor: A YouTuber responde ao comentador;

e) Perguntas: O comentador pergunta algo que não ficou claro na postagem;

f) Colaboração: O comentador interage com o autor com dicas de conteúdo futuros ou indicando que pode fazer algo diferente do que fez no vídeo;

g) Spam: $\bigcirc$ comentador promove seu site ou redes sociais;

h) Críticas: O comentador julga algum comportamento presente no vídeo:

i) Migrantes: $O$ comentador diz que vem de outra rede social do autor;

j) Aleatórios: $O$ comentador menciona coisas que não tem nenhuma relação com o vídeo;

Desacatos: O comentador espalha ódio, preconceito, entre outras incivilidades

Quadro 3. Classificação dos tipos de comentários nos

vídeos mais comentados de cada categoria: a) Identificação com o autor - b) Elogios c) Interação com outros usuários - d) Resposta do Autor - e) Perguntas

f) Colaboração - g) Spam - h) Críticas - i) Migrantes - j) Aleatórios - k) Desacatos

\begin{tabular}{|c|c|c|c|c|c|c|c|c|c|}
\hline Categ & Publi. & Pessoal & Moda & Beleza & Recebidos & Tec e Fot & Viagens & Colab & Total \\
\hline $\mathrm{a}$ & 10 & 87 & - & 1 & 18 & 6 & 2 & 4 & $\mathbf{1 2 8}$ \\
\hline $\mathrm{b}$ & 18 & 131 & 90 & 194 & 32 & 59 & 28 & 325 & $\mathbf{8 7 7}$ \\
\hline $\mathrm{c}$ & 5 & - & - & 14 & 2 & 3 & 2 & 88 & $\mathbf{1 1 4}$ \\
\hline $\mathrm{d}$ & 5 & 42 & 1 & 5 & 39 & 4 & 21 & 31 & $\mathbf{1 4 8}$ \\
\hline $\mathrm{f}$ & 9 & 1 & - & 10 & 7 & 10 & 8 & - & $\mathbf{4 5}$ \\
\hline $\mathrm{f}$ & 6 & - & 18 & 9 & 37 & 8 & 1 & 19 & $\mathbf{9 8}$ \\
\hline $\mathrm{g}$ & 7 & 3 & 5 & 1 & 7 & 3 & 1 & 10 & $\mathbf{3 7}$ \\
\hline $\mathrm{h}$ & 4 & - & - & 1 & 2 & 3 & 1 & 26 & $\mathbf{3 7}$ \\
\hline $\mathrm{i}$ & - & 1 & 3 & 1 & 3 & 4 & - & 1 & $\mathbf{1 3}$ \\
\hline$j$ & 1 & 3 & - & 2 & 1 & - & 6 & 9 & $\mathbf{2 2}$ \\
\hline $\mathrm{k}$ & - & - & - & - & - & - & - & - & $\mathbf{0}$ \\
\hline
\end{tabular}

Fonte: Elaboração das autoras (2020)

De tudo que foi postado nos comentários pela audiência do canal, um ponto que chama atenção é a ausência de postagens do tipo Desacatos. Dos 1.519 comentários, nenhum se enquadrou nessa categoria. Isso aponta para duas possibilidades: uma seria o controle de conteúdo, mesmo a autora afirmando em entrevista que não impede ou exclui postagens de comentadores, porém, a mesma admitiu que já desativou posts inadequados no seu primeiro vídeo; outra possibilidade seria para uma exceção a uma prática bem comum em outras redes.

Seja qual for o motivo, o fato é que para manter um nível de confiabilidade e, em certo grau de liberdade nas postagens, o canal não exclui as postagens de críticas ao conteúdo, pois há 37 postagens de críticas, número irrisório em relação ao montante de postagens de leitores e, ainda assim, só aparecem críticas de cunho polido. Por exemplo, o vídeo da categoria Colaboração, com a maior quantidade de comentários, é o que recebe o maior número de críticas, totalizando 26. A postagem mostra Victória recebendo a digital influencer[9] Taciele Alcolea- com mais de 7 milhões de seguidores - afim de ajudá-la a montar um look. Contudo, a convidada passa a ser julgada 
Só acho a a sola tava nova e a jaqueta já estava com etiqueta(COMENTADOR 1)

"uso muito" e ta com etiqueta kkkkkkkkkkkkk aiai (COMENTADOR 2)

Comportamento semelhante é encontrado na categoria Publieditorial. O vídeo em questão mostra a autora dando dicas de como fazer o cabelo crescer mais rápido com produtos cuja marca pagou para que fosse incluída em seu conteúdo. Os comentários surgem em tons de desaprovação, porém, não chegam a serem agressivos, mas sim como forma de questionamentos sobre a veracidade da informação ali incluída, já que a própria Victória há um ano teria produzido conteúdos similares.

Produto ta notável que foi
utilizado no máximo 1 ou 2
vezes, e a dois meses atrás
você fez outro publi
falando que usava a linha
do johnfrieda.fica difícil
assim a gente, tuas
leitoras, acreditar no que
tu realmente usa, né? Só
acho que seria interessante
que tu fizesses um vídeo
com produtos que tu
realmente ama, que
realmente fizeram a
diferença pro teu cabelo,
que ta tão bonito agora e
grande! Só isso, sabe? Na
internet tem tanta
enganação, que quando a
gente vê alguém que a
gente gosta e segue
fazendo algo que não
parece muito verdadeiro,
precisei comentar
(ComENTADoR 3).

Outra particularidade é que a maioria dos comentários encontrados são elogios e identificação pessoal. Por exemplo, o vídeo de Caráter Pessoal, apesar de não ter sido - mais comentado, totaliza 81,3\% de comentários de elogios e identificação com a vlogueira. No vídeo, a autora narra uma mudança em sua vida, pois ela irá morar com seu namorado. Muitos seguidores enviam mensagens motivadoras e se reconhecem com o conteúdo.

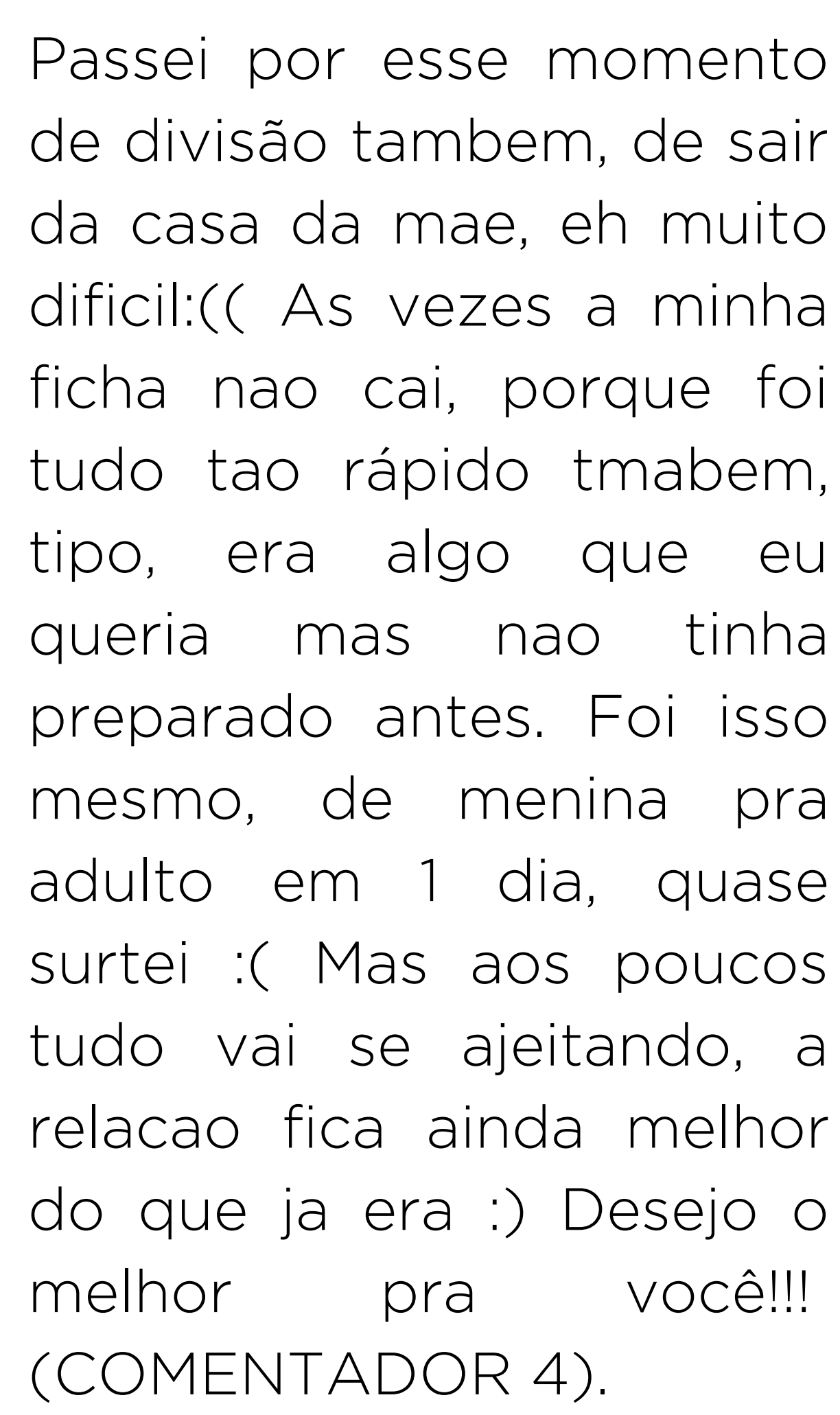
(COMENTADOR 4).

O elogio ao conteúdo ou à autora permite pensar em como a proximidade instiga a interação com o autor do conteúdo. Neste formato de conteúdo a maioria dos comentários não instiga a interação entre seguidores, mas diretamente com o produtor. Outra "novidade" é o índice de respostas encontradas, ao todo são 148 feedbacks documentados por Victória, sendo o segundo tipo de comentário mais presente no canal. Para Rocha (2017), apesar de ela ler todos os comentários postados nos vídeos, não existe nenhum critério para respondê-los, entretanto ela opta por sanar dúvidas ou perguntas dos comentadores.

Colaboração de comentaristas com indicação para conteúdos futuros concluem 98 comentários, contudo, boa parte dessas sugestões ocorre apenas quando Victória pede aos seus inscritos opinarem sobre o que querem ver no canal. Isso mostra que a colaboração ainda é pequena no sentido de complementar o conteúdo e só ocorre quando instigada.

\begin{abstract}
Adoro and faz vídeos de looks, VC poderia tbm antes $d$ ir mostrando os looks fazer uns takes da make e do hair e em seguida mostrar o look Fazer maquia e fala( seria ótimo) . ah, fazer \#viihresponde Big Bjs (COMENTADOR 5).
\end{abstract}

Postagens com Spam totalizam 37 comentários, mesmo número das críticas e são poucos em relação aos dados mundiais. Segundo Nexgate apud Alberto et all (2015, s/p.) "para cada spam encontrado em qualquer rede social, há outros 200 presentes no Facebook e YouTube". Os comentários Aleatórios como "manda beijo pra mim" ou "primeiro a comentar" também foram escassos, atingindo menos que $1 \%$ do total de interações nos vídeos, assim como os comentários

intituladosMigrantes.

\section{CONCLUSÃO}

Ao que parece, depois de analisar as postagens de comentários no canal da vlogueira Victória Rocha podemos concluir que a interação no canal é, efetivamente, um espaço para admiradores. Como não foram encontrados comentários agressivos, fruto de um controle da proprietária da página ou de um seleto grupo de seguidores, o fato é que ali estão, na sua maioria, posts elogiosos. $O$ fato surpreende, inicialmente, porque a vlogueira nega um controle das inserções, mas admite ter excluído um vídeo com muitas inserções negativas. Além disso, causa 
estranhamento, porque o canal como outros, se assemelha muito com blogs - pessoais, temáticos, especializados -, mesmo assim sem atrair as tradicionais posturas selvagens do internauta.

Mas, para além das postagens de elogios, interações marcadas pela relação direta com a produtora do conteúdo também podem ser entendidas com um diferencial. Estudo de Bueno (2015) já tinha mostrado que o comentarista, em algum momento, dirige-se ao produtor do conteúdo, em geral ao jornalista ou ao próprio veículo, embora em pequena escala, sendo a maioria das postagens de interação entre os próprios consumidores da informação. Sendo assim e sem entrar na ceara de exclusão ou não dos posts de leitores que desagradam a produtora do conteúdo, o fato é que a grande maioria dos comentários ali encontrados tratam do assunto e, mais que isso, são dirigidos diretamente a responsável por eles. Isso pode, em certo grau, ser, também, um modo de pensar no comentador como um fã que usa a plataforma para dialogar com o responsável pela informação a ele dirigida.

Tal ponto é um resultado peculiar da pesquisa se levarmos em conta que muitos estudos - Bueno (2015), Bueno et al. (2016) e Sakamoto (2016) - mostram que nas postagens em geral de comentários nas notícias de jornais ou blogs há muito conteúdo que pouco ou nada dialoga com o tema da postagem original. Nesta pesquisa, a plataforma do YouTube se mostrou como um espaço cujo conteúdo, efetivamente, tratou do tema, o que pode ser um caso específico da vlogueira cearense, ou quem sabe uma peculiaridade da própria rede, ou, ainda, uma característica de postagens em conteúdos pensados para público segmentados. Questões que são levantadas a partir deste estudo e que podem instigar outras investigações.

Outro ponto que se levanta nessas considerações finais é sobre a participação da própria produtora do conteúdo. Tais como nos blogs, a vlogueira mostrou que é um hábito responder as postagens, ainda que não tenha um padrão ou tipo de conteúdo que a leve a responder. De qualquer modo, o fato de oferecer o feedback ao seguidor é, também, uma distinção, uma vez que os veículos não costumam adotar essa postura e as respostas sejam, verdadeiramente, uma raridade entre os suportes tradicionais da mídia.

Ainda no âmbito do conteúdo, o que se pode notar ao analisar as postagens dos seguidores do canal é uma colaboração rara e pouco espontânea, o que permite pensar que os comentários estão muito mais próximos de uma participação, atrelada ao consumo; do que um desejo de contribuir para a construção desse conteúdo. Por fim, acredita-se que esse é um breve olhar para os comentários na plataforma e que outras investidas, focadas em interação, colaboração ou postura de internautas poderão ser aviltadas adiante, neste ou em outros canais da rede.

\section{NOTAS}

[1] Somando as contas nas suas redes sociais, Victória Rocha possui mais de 490.000 seguidores.
[2] Autora do blog Rica de Marré (http://ricademarre.com.br/) e com mais de um milhão de seguidores nas redes sociais.

[3] Autora do blog Mari Dalla (http://www.maridalla.com.br/) e com mais de 216 mil seguidores nas redes sociais

[4] Disponivel no original em: https://en.oxforddictionaries.com/defi nition/YouTuber. Acesso em: 26 maio 2020.

[5] São quase 20 milhões de inscritos de acordo com o site de estatísticas do YouTube: Socialblade. Disponível em: https://socialblade.com/ YouTube/user/whinderssonnunes Acesso em: 26 maio 2020

[6] Disponível em

https://www.YouTube.com/watch $v=Z Q f R d C f b 8 f O \& t=2 s$. Acesso em 26 maio de 2020

[7] Composição de peças que resultam num estilo característico.

[8] Material de divulgação enviado por marcas ou assessorias para a imprensa e/ou pessoas com grande influência.

[9] Pessoas que acumulam bastante seguidores em diversas plataformas digitais.

\section{REFERÊNCIAS}

ALBERTO, Túlio Caio; JOHANNES Von Lochter, ALMEIDA, Tiago. Filtragem Automática de Spam nos Comentários do YouTube. (2015). Disponível em: https://cutt.ly/aySVKKL. Acesso em: 20 de mar 2017

BARDIN, Laurence. L'Analyse de contenu. Paris: Editora Presses Universitaires de France, 1977.

BARDIN, Laurence. Análise de conteúdo. São Paulo: Edições 70, 2011.

BARBOSA, Elisabete. Interactividade: A grande promessa do Jornalismo Online. (2001). Disponível em: https://cutt.ly/FySVX6p. Acesso em O2 jan. 2017 
BUENO, Thaísa Cristina. Para que servem os comentários de leitores na internet? Estudo sobre a utilidade da ferramenta nos sites de notícias a partir da estrutura do dispositivo e do modo de apropriação do internauta e do veículo. 2015. Tese (Doutorado em Comunicação Social). Programa de Pós-Graduação em Comunicação Social, Pontifícia Universidade Católica do Rio Grande do Sul, Porto Alegre, 2015. Disponível em: https://cutt.ly/aySBfPv. Acesso em: 02 de fev. 2017

- Como pesquisadores e veículos têm tratado o tema comentário de leitores na internet. Revista Liinc, 12(1), p.180-194, 2016. Disponivel

em: https://cutt.ly/OySVObG. Acesso em: 16 de mar. 2017.

BUENO, Thaísa; REINO, Lucas Santiago Arraes. Comentários na Internet. Imperatriz: Edufma, 2014. Disponível em: https://cutt.ly/5ySBtr3. Acesso em: 20 dez. 2016

BUENO, Thaísa; REINO, Lucas Santiago Arrraes; HOLANDA, Letícia; ARAÚJO, Gustavo; ESCÓclO, Even Grazielly. Comentários de leitores na internet: um olhar sobre a opinião do internauta. Revista Comunicando, 5(2), p.88-103, 2016. Disponível em: https://cutt.ly/fySByEO Acesso em: 03 fev. 2017.

BURGESS, Jean; GREEN, Joshua. YouTube e a Revolução Digital: como - maior fenômeno da cultura participativa transformou a mídia e a sociedade. São Paulo: Aleph, 2009.

CAMPOS, Mario; et al. Mensajes de odio y discriminación en las redes sociales. México: Conapred, 2015. Disponível https://cutt.ly/JySBiZB. Acesso em: 14 jan. 2017.

DORNELLES, Juliano Paz. O fenômeno Vlog no YouTube: análise de conteúdo deVloggers brasileiros de sucesso. (2014). Dissertação (Mestrado em Comunicação Social). Programa de Pós-Graduação em Comunicação Social, Pontifícia Universidade Católica do Rio Grande do Sul, Porto Alegre, 2014. Disponível em: https://cutt.ly/JySBdJL. Acesso em: 31 de dez. 2016.
FIGUEIRA, Artur Felipe Titon BASSANI, Renata; EMERIM, Cárlida. Canal SWITCH - uma experiência de jornalismo YouTuber. In: Anais do Congresso de Ciências da Comunicação na Região Sul INTERCOM, 2016, Curitiba-PR. Anais... São Paulo: Intercom, 2016. Disponíve em: https://cutt.ly/5ySBg5p. Acesso em: 04 de fev. 2017

GANNES, Liz. Jawed Karim: How YouTube Took Off. (2006) Disponivel em: https://cutt.ly/VySBhBU. Acesso em: 14 de outubro de 2016.

GASKELL, George. Entrevistas individuais e grupais. In: BAUER, Martin; GASKELL, George (Orgs.) Pesquisa qualitativa com texto, imagem e som: um manual prático. Petrópolis: Vozes, 2002, p.64-89.

GIL, Antônio Carlos. Como elaborar projetos e pesquisa. São Paulo: Atlas; 1995

GILLESPIE, Tarleton. The politics of "platforms." New Media \& Society, 12(3), p.347-364. 2010

GODOY, Arilda Schmidt. Pesquisa qualitativa: tipos fundamentais. Revista de Administração de Empresas, 35(4), p.65-71, 1995

JENKINS, Henry; FORD, Sam; GREEN, Joshua. Cultura da conexão: criando valor e significado por meio da mídia propagável. São Paulo: Editora Aleph, 2014

KEEN, Andrew. O culto do amador: como blogs, MySpace, YouTube e a pirataria digital estão destruindo nossa economia, cultura e valores. Rio de Janeiro: Jorge Zahar, 2009.

MAGDA, Maria. O Estudo de Caso como Modalidade de Pesquisa. Socerj. 1(20), p.383-386, 2007 Disponível https://cutt.ly/1ySNqeB. Acesso em O2 de jul. 2017

MORAES, Roque. Análise de conteúdo. Revista Educação, 22(37), p. 7-32, 1999. Disponível em: https://cutt.ly/hySNa8r. Acesso em: O2 de jul. 2017
PRIMO, Alex; SMANIOTTO, Ana Maria Reczek. Blogs como espaços de conversação: interações conversacionais na comunidade de blogs insanus. e-Compós, 1(5), p

1-21, 2006. Disponivel em: https://cutt.ly/PySB500 Acesso em: 05 fev. 2017

ROCHA, Victória. Entrevista com Victória Rocha para esta pesquisa. [Entrevista concedida à Even Grazielly de Sousa Escócio Silva] por meio do aplicativo Whatsapp. 19 abr. 2017.

SAKAMOTO, Leonardo. O que aprendi sendo xingado na internet. São Paulo: Leya, 2016.

SANTOS, Bruna Ribeiro Bomfim; SILVA, Letícia Machado; ZATTAR, Marianna. YouTube Como Fonte de Informação Para o Mercado de Moda e Beleza. Biblionline, João Pessoa, 12(1), p.86-95, 2016. Disponível em: https://cutt.ly/bySNol3. Acesso em: O2 jan. 2017

SERRANO, Paulo Henrique Souto Maior; PAIVA, Claudio. (2008). Critérios de categorização para os vídeos do YouTube. In: Anais do Congresso de Ciências da Comunicação na Região Sul INTERCOM, 2008, Natal-RN-PR. Anais... Natal: Intercom, 2008. Disponível em: https://cutt.ly/FySB8EW. Acesso em: 14 out. 2016

THINK WITH GOOGLE. A inspiração vira desejo. 2016a. Disponível em: https://cutt.ly/mySNhXJ. Acesso em: 14 out. 2016

Beleza não é só uma categoria. É um statement. 2016b. Disponível em: https://cutt.ly/KySNjts. Acesso em: 14 out. 2016. https://cuttly/OySNink. Acesso em: out. 2016.

O Lampião (e Fênix) do YouTube. 2016d. Disponível em: https://cutt.ly/bySNj7B. Acesso em: 14 out. 2016.

VIIHROCHA. Disponível em: https://www.YouTube.com/user/viihro cha. Acesso em: 14 nov. 2016. 
WARD, Mike. Jornalismo online. São Paulo: Roca, 2007.

YOUTUBE PARA A IMPRENSA. Youtube. (2020). Disponível em: https://cutt.ly/yySNC8t. Acesso em: 03 de mai. 2020

\section{REFERÊNCIAS AUDIOVISUAIS}

VIIHROCHA. 4 Penteados estilo Tumblr. Publicado no YouTube. 19 maio 2016. 1 vídeo (5 min.). Disponível em: https://cutt.ly/LySNFvl. Acesso em: 17 maio 2016

5 Dicas para o seu cabelo crescer mais rápido. Publicado no YouTube. 15 set. 2016. 1 vídeo (8 min.). Disponível: em https://cutt.ly/tySNIHI. Acesso em: 17 maio

2016

6 looks com lace up flats Get the look. Publicado no YouTube. 23 dez. 2015. 1 vídeo (4 min.). Disponível

em: https://cutt.ly/MySNSi2. Acesso em: 17 maio 2016

Como edito minhas fotos - Apps preferidos, branquear foto. Publicado no YouTube. 12 out. 2015. Disponível em: https://cutt.ly/1ySN7gG. Acesso em: 17 maio 2016 YouTube. 20 set. 2016. 1 vídeo (9 min.). Disponível em: https://cutt.ly/gySMahc. Acesso em: 17 maio 2016

Recebidos de Outubro. Publicado no YouTube. 12 out. 2015. 1 vídeo (15 min.). Disponível em: https://cutt.ly/HySN9QX. Acesso em: 17 maio 2016.
Top of the rock - vlog New York, episódio 2. Publicado no YouTube. 01 set. 2015. 1 vídeo (23 min.). Disponível em: https://cutt.ly/EySN5ck. Acesso em: 17 maio 2016

Uma nova fase das nossas vidas! Publicado no YouTube. 05 ago. 2016. 1 vídeo (21 min.). Disponível em: https://cutt.ly/3ySNWjG. Acesso em: 17 maio 2016

\section{Artigo recebido em: 15 Jan 2020. I Artigo aprovado em: 04 Maio 2020.}

[i] Doutora em Comunicação pela Pontifícia Universidade Católica do Rio Grande do Sul (PUC-RS), Mestre em Letras pela Universidade Federal do Mato Grosso do Sul (UFMS) - Campus de Três Lagoas, Graduada em Comunicação Social pela Universidade Federal do Mato Grosso do Sul (UFMS). É professora permanente no Programa de Pós-Graduação em Comunicação, na Universidade Federal do Maranhão (UFMA). Coordena o Grupo de Pesquisa em Comunicação em Cibercultura (GCiber) e integra o Grupo de Pesquisa em Ciberjornalismo, numa parceria entre a UFMA e a UFMS. Possui pesquisas financiadas pela CAPES/ FINANCE CODE 001 e FAPEMA, por meio do edital Universal de 2018.

Orcid: http://orcid.org/0000-0002-7048-3920.

E-mail: thaisabu@gmail.com

[ii] Jornalista formada pela Universidade Federal do Maranhão (UFMA) de Imperatriz. Integrante do Grupo de Pesquisa em Comunicação e Cibercultura (GCiber) na mesma instituição. Atuou por quatro anos no grupo como bolsista PIBIC, com bolsas financiadas pelo CNPq e FAPEMA

Orcid: http://orcid.org/0000-0003-3320-4571

E-mail: graziellyescocio@gmail.com 